\title{
Nurse practitioners in accident and emergency departments: what do they do?
}

\author{
Susan M Read, Nicola M B Jones, Brian T Williams
}

\begin{abstract}
Objective-To determine the distribution and scope of nurse practitioner schemes in accident and emergency departments in England and Wales; to describe the caseloads of doctors and nurse practitioners on two representative days; and to estimate the number of patients managed by nurse practitioners in the year to 31 March 1991.

Design-A postal survey of accident and emergency departments and a content analysis of case notes of new patients attending a representative sample of accident and emergency departments on two days.
\end{abstract}

Setting-All accident and emergency departments in England and Wales.

Participants-Survey: 560 nurses in charge of accident and emergency departments. Census: case notes of 5814 patients in 37 accident and emergency departments.

Main outcome measures-Survey: number of accident and emergency departments with nurse practitioner schemes. Census: demographic and clinical characteristics of new patients attending and whether nurse practitioner or doctor made diagnoses and ordered investigations, treatments, referrals, discharges.

Results-513 replies $(92 \%)$ from 465 surveyed functioning accident and emergency departments and 48 departments recently closed. $27(6 \%)$ departments used designated nurse practitioners and 159 $(34 \%)$ "unofficial" nurse practitioners. Only $530(9 \%)$ of the 5814 patients in the census were managed entirely or mainly by nurse practitioners, with higher proportions in ophthalmic departments (nearly $30 \%$ and minor casualty departments (over $40 \%$ ) than in major departments $(3 \%)$. Most patients managed by nurse practitioners $(86 \%)$ had minor trauma. In the year ending 31 March 1991 an estimated $390000 \quad(95 \%$ confidence interval 260000 to 520000 ) patients out of a total of $12 \cdot 5$ million $(3 \cdot 1 \%, 2 \cdot 1 \%$ to $4 \cdot 1 \%)$ were clinically managed by a nurse practitioner.

Conclusions-Designated nurse practitioner schemes are rare. The volume and range of nurse practitioner work in major general accident and emergency departments is small compared with those in specialised and minor accident and emergency departments.

Medical Care Research Unit, Department of Public Health Medicine, University of Sheffield Medical School, Sheffield S10 2RX

Susan M Read, nurse research associate

Nicola M B Jones,

statistician

Brian T Williams, director

Correspondence to: Dr Read.

\section{Introduction}

In the past decade an officially recognised nurse practitioner role has emerged in some major accident and emergency departments in Britain, ${ }^{1-3}$ following North American examples. ${ }^{+7}$ This innovation is one attempt to cope with an increasing number of patients, ${ }^{\text {" }}$ many with relatively minor conditions. ${ }^{4.12}$ For many years before, nurses in minor injury and ophthalmic units assessed and treated suitable patients independently and often unofficially. ${ }^{1314}$

No nationally recognised training exists for nurse practitioners in accident and emergency, although the Royal College of Nursing has considered this for some time ${ }^{15}$; some accident and emergency departments arrange their own training schemes.

Concern over the possible piecemeal development of nurse practitioner schemes in the light of cuts in junior doctors' hours prompted the study reported here of the work of nurse practitioners in accident and emergency $\vec{\omega}$ departments. Previous research on the topic in Britain $\stackrel{\vec{\sigma}}{\circ}$ has been minimal, ${ }^{1617}$ so we planned a survey in England and Wales to determine the distribution and scope of nurse practitioner schemes, followed by a two $O$ day retrospective census of accident and emergency case notes in selected departments to compare the $\mathscr{\circ}$ respective clinical responsibilities and caseloads of. nurse practitioners and doctors.

Method

SURVEY

A questionnaire, developed in a pilot study in the $40 \mathbb{\Phi}$ accident and emergency departments in Trent region, $\overparen{\AA}$ was addressed to the "nurse in charge" of each of the 560 accident and emergency departments in England $\stackrel{\Phi}{-}$ and Wales listed in the 1990 handbook of the Casualty $\vec{\varphi}$ Surgeons' Association." For the purposes of the $\mathrm{N}$ survey, a nurse practitioner was defined as:

A nurse who is authorised to assess and treat patients attending an accident and emergency department, either as an alternative to the patient being seen by a doctor, or in the absence of a doctor in a department where a continuous $\frac{\text { }}{\mathrm{D}}$ medical presence is not maintained. Some nurses function as $\varrho$ nurse practitioners without actually holding the title.

We asked about the type of department (classified as major, usually in district general hospitals with a 24 F hour medical presence; specialist, such as ophthalmic or paediatric; or minor, usually in community hospitals with general practitioners on call); about numbers of new patients in the year to 31 March 1991; 욱 about nurse practitioner activity; and whether the nurse practitioner scheme was official (using the title) or unofficial (not using the title).

A postal reminder was sent to non-respondents after응 three weeks, and telephone inquiries were made both $N$ to verify the continuing existence of smaller non- $\rightarrow$ responding departments and to clarify ambiguous responses to questions. Survey data were analysed with the Epi-Info statistical computing package. ${ }^{19}$

CENSUS

Having established the reported prevalence, distribution, and scope of official and unofficial nurse $\overparen{\Phi}$ practitioner schemes in major, minor, and specialist ${ }_{-}^{-}$ hospitals, we then excluded from our list of $186^{\circ}$ accident and emergency departments reporting nurse $\underset{\mathbb{D}}{\mathrm{D}}$ practitioner schemes any department with fewer than $\frac{\Omega}{\mathbb{D}}$ 8000 new patient attendances in the previous year- $\varrho$ that is, fewer than 22 new attendances a day. Our resources did not permit visits to so many departments. 8 Four specialist and 103 minor departments were thuse excluded $-70 \%$ of the minor departments excludedô actually saw fewer than 11 new patients a day, $\stackrel{\rightleftharpoons}{\risingdotseq}$ including all three minor departments with official practitioners.

The remaining 79 hospitals were grouped by NHS 
region within separate lists of major, specialist, and minor accident and emergency departments, and whether their nurse practitioner schemes were official or unofficial. One department of each type from each region was selected, wherever possible, giving a total of 40 departments -20 major and two paediatric, six ophthalmic, and 12 minor. Some regions were not represented in some lists; where several departments of the same type were eligible within a region we chose the departments with the highest level of nurse practitioner autonomy according to the survey results. If these were equal the selection was made with a random number table.

A Tuesday and a Sunday in June 1991 (0000 hours to 2359) were selected retrospectively for the records census, avoiding public holidays; the dates were thought to be unexceptional, ${ }^{20}$ and should have shown any difference between weekdays and weekends in staff availability and patient attendance.

For each new patient attending on the specified dates demographic and clinical characteristics and whether a doctor or nurse practitioner had made the diagnosis and ordered investigations, treatments, referral, or disposal were recorded. A list of 30 commonly occurring presenting problems was coded, as were the diagnosis, investigation, treatment, referral, and disposal in each case. In a small number of case notes decisions by both categories of staff were recorded. These patients were allocated to the groups "managed by doctor" or "managed by nurse practitioner," according to who took most of these management decisions.

The coded data were analysed with the SPSSX package.

\section{Results}

SURVEY

Replies were received relating to $513(92 \%)$ of the 560 departments in England and Wales. Forty eight responding departments were reported to have closed since the casualty surgeons' handbook was published, leaving 465 still active.

Official nurse practitioner schemes were reported in only $27(6 \%)$ of the 465 departments. They were more common in major accident and emergency departments (20 out of $213,9 \%$ ) and specialist (ophthalmic and paediatric) departments (4 out of $25,16 \%$ ) than minor ones ( 3 out of $227,1 \%$ ). In contrast, unofficial nurse practitioner schemes were reported in 159 departments $(34 \%)$, more commonly in specialist departments ( 12 out of $25,48 \%$ ) and minor injury units (131 out of $227,58 \%$ ) and less frequently in major departments ( 16 out of $213,8 \%$ ).

All NHS regions except North West Thames, South Western, and Wales contained at least one official nurse practitioner scheme. Every region had at least one unofficial scheme; their heaviest concentration was in regions with largely rural populations and many

TABLE I-Number and percentage of patients managed by nurse practitioners according to type of department and nurse practitioner scheme on two census days

\begin{tabular}{|c|c|c|c|c|c|c|c|}
\hline \multirow[b]{2}{*}{$\begin{array}{l}\text { Type of } \\
\text { department } \\
\text { and nurse } \\
\text { practitioner } \\
\text { scheme }\end{array}$} & \multirow[b]{2}{*}{ No } & \multicolumn{2}{|c|}{ Tuesday 4 June } & \multicolumn{2}{|c|}{ Sunday 9 June } & \multicolumn{2}{|c|}{ Both days combined } \\
\hline & & $\begin{array}{c}\text { Total } \\
\text { new } \\
\text { patients }\end{array}$ & $\begin{array}{l}\text { No }(\%) \\
\text { managed by } \\
\text { nurse } \\
\text { practitioner }\end{array}$ & $\begin{array}{l}\text { Total } \\
\text { new } \\
\text { patients }\end{array}$ & $\begin{array}{l}\text { No }(\%) \\
\text { managed by } \\
\text { nurse } \\
\text { practitioner }\end{array}$ & $\begin{array}{c}\text { Total } \\
\text { new } \\
\text { patients }\end{array}$ & $\begin{array}{c}\text { No }(\%) \\
\text { managed by } \\
\text { nurse } \\
\text { practitioner }\end{array}$ \\
\hline Major official & 13 & 1582 & $58(3 \cdot 7)$ & 1717 & $32(1.9)^{\star}$ & 3299 & $90(2 \cdot 7)$ \\
\hline Major unofficial & 7 & 684 & $19(2 \cdot 8)$ & 766 & $24(3 \cdot 1)$ & 1450 & $43(3 \cdot 0)$ \\
\hline Ophthalmic official & 3 & 157 & $33(21)$ & 102 & $40(39)^{\star \star}$ & 259 & $73(28)$ \\
\hline Ophthalmic unofficial & 3 & 97 & $23(24)$ & 50 & $20(40)$ & 147 & $43(29)$ \\
\hline Minor unofficial & 11 & 314 & $143(46)$ & 345 & $138(40)$ & 659 & $281(43)$ \\
\hline All departments & 37 & 2834 & $276(9 \cdot 7)$ & 2980 & $254(8.5)$ & 5814 & $530(9 \cdot 1)$ \\
\hline
\end{tabular}

Test of difference in proportions of patients managed by a nurse practitioner between the two days: ${ }^{\star} \chi^{2}{ }_{t}=9 \cdot 413$, $\mathrm{p}<0.005 ;{ }^{\star \star} \chi^{2 / 14}=9 \cdot 235, \mathrm{p}<0 \cdot 005$. minor injury units (Wessex, South Western, and Wales).

\section{CENSUS OF CASE NOTES}

Despite selection for the census of departments reporting higher levels of nurse practitioner autonomy in the previous survey, three were found later to be ineligible, reducing the number of participating departments to 37 . (Consultants in one major, one minor, and one paediatric department reported that new patients always saw a doctor.)

A total of 6208 new patients had attended the 37 departments over the two days; $5814(94 \%)$ case notes were located and examined; $7 \%$ of notes in major departments were missing, $1 \%$ in minor departments, and $6 \%$ in ophthalmic departments. Only $530(9 \%)$ of these 5814 patients were managed entirely or predominantly by nurse practitioners in the departments overall (table I), of whom $32(6 \%)$ received one component of their care from a doctor (usually a prescription). Of the 5241 patients for whom doctors took the major decisions, only $29(0.5 \%)$ were also seen by nurse practitioners, usually for initial assessment before referral to medical care. Another 43 patients were seen by other staff, usually triage nurses, but did not wait for treatment. Differences between the proportions of patients managed by nurse practitioners on the two days were significant only in the major (relatively more on the weekday) and ophthalmic departments (more on the Sunday) with official nurse practitioners.

Patients were less likely to be managed by nurse practitioners in the major accident and emergency departments, despite their higher patient numbers. In official schemes suitability was decided according to a protocol which typically specified age groups, parts of the body, and types of accident. Among the 20 major departments, 16 combined the role of nurse practitioner and triage nurse, with the triage encounter being extended to include decisions on diagnosis and management in suitable cases. In two major departments triage and nurse practitioner roles were always kept separate: the triage nurse referred patients to the practitioner according to a protocol. In the two other departments no triage was performed and the decision to refer to a nurse practitioner rested with the receptionists. All six ophthalmic departments had triage schemes, usually combined with the nurse practitioner role; patients were referred to doctors according to protocols. In all 11 minor departments patients were seen first by an unofficial nurse practitioner who called the doctor only for cases outside accepted categories. Some of these departments used written protocols, some did not, but protocols were not as detailed or restrictive as in major departments.

Extrapolation from both census and survey data, by using appropriate reweighting factors to account for sizes of department and presence of nurse practitioner schemes, gave an estimate that out of 12500000 new patients who attended accident and emergency departments in England and Wales in the year ending 31 March 1991, only 390000 (95\% confidence interval 260000 to 520000$)$ or $3 \cdot 1 \%$ at most $(2 \cdot 1 \%$ to $4 \cdot 1 \%)$ of all new accident and emergency patients would have been managed by nurse practitioners. ${ }^{21}$

\section{Patient characteristics}

Doctors and nurse practitioners managed similar proportions of men (59\%) and women $(41 \%)$. The median age of doctor managed patients (irrespective of type of department or nurse practitioner scheme) and of nurse practitioner managed patients was the same25 years; relatively more cases managed by doctors 
were in children under 5 years $(12 \% v 8 \%)$ and people over 65 years $(10 \% v 5 \%)$

\section{Presenting problems and their management}

Nurse practitioners' caseloads contained relatively more trauma $(86 \% ; 453 / 529)$, albeit minor, than did doctors' (73\%; 3832/5234). Nurse practitioners also managed a narrower range of presenting problems than doctors (tables II and III). Most problems managed by nurse practitioners were the common conditions arising from small accidents-cuts, splinters, etc. Many of the nurse practitioner protocols excluded head injuries. In a minority of departments (4 major 5 minor), however, $14(3 \%)$ of the nurse practitioners'

TABLE II-Distribution of problems presented to doctors and nurse practitioners respectively in major and minor general accident and emergency departments. Results are numbers (percentages)

\begin{tabular}{|c|c|c|c|c|c|c|}
\hline \multirow[b]{2}{*}{ Problem } & \multicolumn{2}{|c|}{$\begin{array}{l}\text { Major departments } \\
\text { with official } \\
\text { nurse practitioners }\end{array}$} & \multicolumn{2}{|c|}{$\begin{array}{l}\text { Major departments } \\
\text { with unofficial } \\
\text { nurse practitioners }\end{array}$} & \multicolumn{2}{|c|}{$\begin{array}{l}\text { Minor departments } \\
\text { with unofficial } \\
\text { nurse practitioners }\end{array}$} \\
\hline & Doctor & $\begin{array}{c}\text { Nurse } \\
\text { practitioner }\end{array}$ & Doctor & $\begin{array}{c}\text { Nurse } \\
\text { practitioner }\end{array}$ & Doctor & $\begin{array}{c}\text { Nurse } \\
\text { practitioner }\end{array}$ \\
\hline Pain & $1247(32)$ & $25(26)$ & $629(36)$ & $10(22)$ & $125(29)$ & $65(21)$ \\
\hline Cut/abrasion & $723(19)$ & $47(49)$ & $341(20)$ & $20(44)$ & $75(17)$ & $113(36)$ \\
\hline Foreign body & $167(4)$ & $5(5)$ & $58(3)$ & $4(9)$ & $16(4)$ & $26(8)$ \\
\hline Sting/bite & $73(2)$ & $7(7)$ & $37(2)$ & $1(2)$ & $11(3)$ & $11(3)$ \\
\hline Swelling/bruising & $409(11)$ & $4(4)$ & $145(8)$ & $5(11)$ & $40(9)$ & $45(14)$ \\
\hline Potential concussion & $271(7)$ & $1(1)$ & $106(6)$ & $1(2)$ & $15(3)$ & $9(3)$ \\
\hline Cardiorespiratory & $109(3)$ & 0 & $63(4)$ & 0 & $33(8)$ & 0 \\
\hline Burn/scald & $79(2)$ & $4(4)$ & $29(2)$ & $1(2)$ & $7(2)$ & $16(5)$ \\
\hline Potential fracture or dislocation & $234(6)$ & 0 & $104(6)$ & 0 & $25(6)$ & $8(3)$ \\
\hline Altered consciousness & $121(3)$ & $2(2)$ & $50(3)$ & 0 & $10(2)$ & 1 \\
\hline Noxious ingestion/contamination & $76(2)$ & $1(1)$ & $19(1)$ & $2(4)$ & 0 & $2(1)$ \\
\hline Infection & $67(2)$ & $1(1)$ & $38(2)$ & $1(2)$ & $17(4)$ & $12(4)$ \\
\hline Other & $264(7)$ & 0 & $127(7)$ & 0 & $62(14)$ & $9(3)$ \\
\hline Total & 3840 & 97 & 1746 & 45 & 436 & 317 \\
\hline Total patients & 3194 & 90 & 1404 & 43 & 355 & 281 \\
\hline
\end{tabular}

TABLE III-Distribution of problems presented to doctors and nurse practitioners respectively in ophthalmic accident and emergency departments. Results are numbers (percentages)

\begin{tabular}{|c|c|c|c|c|}
\hline \multirow[b]{2}{*}{ Problem } & \multicolumn{2}{|c|}{$\begin{array}{l}\text { Ophthalmic departments with } \\
\text { official nurse practitioners }\end{array}$} & \multicolumn{2}{|c|}{$\begin{array}{l}\text { Ophthalmic departments with } \\
\text { unofficial nurse practitioners }\end{array}$} \\
\hline & Doctor & $\begin{array}{c}\text { Nurse } \\
\text { practitioner }\end{array}$ & Doctor & $\begin{array}{c}\text { Nurse } \\
\text { practitioner }\end{array}$ \\
\hline Pain & $52(28)$ & $12(16)$ & $35(32)$ & $4(9)$ \\
\hline Foreign body in eye & $31(16)$ & $41(55)$ & $14(13)$ & $19(44)$ \\
\hline Infection in eye & $40(21)$ & $15(20)$ & $20(18)$ & $11(26)$ \\
\hline Cut/abrasion & $2(1)$ & $1(1)$ & 0 & $6(14)$ \\
\hline Visual disturbance & $26(14)$ & $1(1)$ & $19(17)$ & $1(2)$ \\
\hline Contamination & 0 & $3(4)$ & $1(1)$ & $1(2)$ \\
\hline Burn/scald eye & $8(4)$ & $1(1)$ & $3(3)$ & $1(2)$ \\
\hline Swelling/bruising & $15(8)$ & 0 & $11(10)$ & 0 \\
\hline Potential fracture near eye & $4(2)$ & 0 & 0 & 0 \\
\hline Haemorrhage (eye) & $6(3)$ & 0 & $5(5)$ & 0 \\
\hline Other & $4(2)$ & 0 & $1(1)$ & 0 \\
\hline Total problems & 188 & 74 & 109 & 43 \\
\hline Total patients & 184 & 73 & 104 & 43 \\
\hline
\end{tabular}

cases were of fainting or head injury with potential concussion. Two of the concussion cases in minor departments were referred directly to major accident and emergency departments; the remaining patients were given instructions about head injury. Only three were not referred for follow up by the general practitioner. Differences in the range of problems managed by official and unofficial nurse practitioners in similar departments were negligible, as were differences between nurse practitioners in major and minor departments.

The only investigations requested by nurse practitioners were radiographs, and these for only $3 \%$ of their patients. Among patients managed by doctors $41 \%$ were investigated; $78 \%$ of these requests were for radiographs.

In major and minor general accident and emergency departments, irrespective of the kind of nurse practitioner scheme in operation, three types of minor trauma (open wounds, contusions, and abrasions) formed about two thirds of nurse practitioners' caseloads and only one third of doctors' caseloads. In major departments, however, nurse practitioners (whether official or unofficial) managed only $90(4 \%)$ of all the 2240 open wounds, contusions, and abrasions, but in minor departments they managed $155(55 \%)$ of the 281 cases. In ophthalmic departments three conditions formed at least four fifths of nurse practitioners' caseloads but less than half of doctors': foreign body in the eye, corneal abrasion, and eye infection. Doctors managed $130(53 \%)$ and nurse practitioners $115(47 \%)$ of the 245 foreign bodies, corneal abrasions, and eye infections. Differences between departments with official and unofficial nurse practitioners were negligible.

Differences between doctors and nurse practitioners in treatments ordered were closely related to the differences in their patients' diagnoses (table IV). Nurse practitioners ordered proportionately more dressings and wound closures and doctors more prescriptions.

Doctors referred relatively more patients for specialist advice than did nurse practitioners in all types of department (table V) but made relatively fewer requests for follow up in all departments except major departments with official nurse practitioners. Nurse practitioners in minor departments had a particularly high follow up rate, usually because their protocols required this. Only $14(3 \%)$ out of 530 patients seen by a nurse practitioner did not go home after treatment, compared with $629(12 \%)$ of the 5241 patients managed by doctors; all 14 were patients initially attending minor injury units who were sent on immediately to

TABLE IV-Distribution of most common treatments ordered in accident and emergency departments by doctors and nurse practitioners. Results are numbers (percentages) of treatments

\begin{tabular}{|c|c|c|c|c|c|c|c|c|c|}
\hline $\begin{array}{l}\text { Type of department } \\
\text { and scheme }\end{array}$ & $\begin{array}{c}\text { Managed } \\
\text { by }\end{array}$ & $\begin{array}{c}\text { No of } \\
\text { patients }\end{array}$ & $\begin{array}{c}\text { No of } \\
\text { treatments }\end{array}$ & $\begin{array}{c}\text { No }(\%) \\
\text { dressing/ } \\
\text { bandage/ } \\
\text { eye pad }\end{array}$ & $\begin{array}{l}\text { No }(\%) \\
\text { wound } \\
\text { closure }\end{array}$ & $\begin{array}{l}\text { Prescription } \\
\text { and/or } \\
\text { immunisation }\end{array}$ & $\begin{array}{l}\text { Advice } \\
\text { only }\end{array}$ & $\begin{array}{c}\text { Remove } \\
\text { foreign } \\
\text { body from } \\
\text { eye }\end{array}$ & Other \\
\hline & & & & General & & & & & \\
\hline \multirow[t]{2}{*}{ Major, official } & Doctor & 3194 & 3965 & $1134(29)$ & $425(11)$ & $1067(27)$ & $762(19)$ & $54(1)$ & $523(13)$ \\
\hline & Nurse practitioner & 90 & 111 & $40(36)$ & $33(30)$ & $17(15)$ & $9(8)$ & 0 & 12 (11) \\
\hline \multirow[t]{2}{*}{ Major, unofficial } & Doctor & 1404 & 1793 & $494(28)$ & $200(11)$ & $523(29)$ & $294(16)$ & $23(1)$ & 259 (14) \\
\hline & Nurse practitioner & 43 & 49 & $16(33)$ & $13(27)$ & $7(14)$ & $10(20)$ & 0 & $3(6)$ \\
\hline \multirow{2}{*}{ Minor, unofficial } & Doctor & 355 & 394 & $103(26)$ & $38(10)$ & $139(35)$ & $75(19)$ & $2(1)$ & $37(9)$ \\
\hline & Nurse practitioner & 281 & 350 & $173(49)$ & $61(17)$ & 47 (13) & $35(10)$ & $12(3)$ & $22(6)$ \\
\hline \multirow{2}{*}{$\begin{array}{l}\text { All general } \\
\text { departments }\end{array}$} & Doctor & 4953 & 6152 & $1731(28)$ & $663(11)$ & $1729(28)$ & $1131(18)$ & $79(1)$ & $819(13)$ \\
\hline & Nurse practitioner & 414 & 510 & $229(45)$ & $107(21)$ & $71(14)$ & $54(11)$ & $12(2)$ & $37(7)$ \\
\hline \multicolumn{10}{|c|}{ Ophthalmic } \\
\hline \multirow[t]{2}{*}{ Official } & Doctor & 184 & 208 & $5(2)$ & & $124(60)$ & $47(23)$ & $18(9)$ & $14(6)$ \\
\hline & Nurse practitioner & 73 & 142 & $29(20)$ & & $70(49)$ & $2(1)$ & $35(25)$ & $6(4)$ \\
\hline \multirow[t]{2}{*}{ Unofficial } & Doctor & 104 & 134 & $16(12)$ & & $67(50)$ & $33(25)$ & $13(10)$ & $5(4)$ \\
\hline & Nurse practitioner & 43 & 79 & $16(20)$ & & $36(45)$ & $5(6)$ & $18(23)$ & $4(5)$ \\
\hline \multirow{2}{*}{$\begin{array}{r}\text { All ophthalmic } \\
\text { departments }\end{array}$} & Doctor & 288 & 342 & $21(6)$ & & $191(56)$ & $80(23)$ & $31(9)$ & $19(6)$ \\
\hline & Nurse practitioner & 116 & 221 & $45(20)$ & & $106(48)$ & $7(3)$ & $53(24)$ & $10(5)$ \\
\hline
\end{tabular}


TABLE $\mathrm{v}-$ Numbers and percentages of patients referred for specialist help or for follow-up in accident and emergency department or by general practitioner, according to type of department and nurse practitioner scheme and by clinical manager

\begin{tabular}{|c|c|c|c|c|c|}
\hline $\begin{array}{l}\text { Type of department and nurse } \\
\text { practitioner scheme }\end{array}$ & Managed by & $\begin{array}{c}\text { No of } \\
\text { patients } \\
\text { managed }\end{array}$ & $\begin{array}{l}\text { No }(\%) \\
\text { referred }\end{array}$ & $\begin{array}{c}\text { No }(\%) \\
\text { followed } \\
\text { up }\end{array}$ & $\begin{array}{l}\text { No }(\%) \text { with } \\
\text { neither } \\
\text { referral nor } \\
\text { follow up }\end{array}$ \\
\hline \multirow[t]{2}{*}{ Major official } & Doctor & 3194 & $775(24)$ & $1105(35)$ & $1314(41)$ \\
\hline & Nurse practitioner & 90 & $4(4)$ & $18(20)$ & $68(76)$ \\
\hline \multirow[t]{2}{*}{ Major unofficial } & Doctor & 1404 & $416(30)$ & $357(25)$ & $631(45)$ \\
\hline & Nurse practitioner & 43 & $1(2)$ & $13(30)$ & $29(67)$ \\
\hline \multirow[t]{2}{*}{ Ophthalmic official } & Doctor & 184 & $35(19)$ & $47(26)$ & $102(55)$ \\
\hline & Nurse practitioner & 73 & 0 & $23(32)$ & $50(68)$ \\
\hline \multirow[t]{2}{*}{ Ophthalmic unofficial } & Doctor & 104 & $10(10)$ & $28(27)$ & $66(63)$ \\
\hline & Nurse practitioner & 43 & 0 & $14(33)$ & $29(67)$ \\
\hline \multirow[t]{2}{*}{ Minor unofficial } & Doctor & 355 & $56(16)$ & $128(36)$ & $171(48)$ \\
\hline & Nurse practitioner & 281 & $17(6)$ & $203(72)$ & $61(22)$ \\
\hline $\begin{array}{l}\text { All patients managed by doctor or } \\
\text { nurse practitioner }\end{array}$ & & 5771 & $1314(23)$ & $1936(34)$ & $2521(44)$ \\
\hline $\begin{array}{l}\text { Patients seen by other staff who did not } \\
\text { wait for treatment }\end{array}$ & & 43 & & & \\
\hline All patients & & 5814 & & & \\
\hline
\end{tabular}

major accident and emergency departments by the nurse practitioners.

\section{Discussion}

Three main conclusions emerge about the work of nurse practitioners in accident and emergency departments. Firstly, official nurse practitioner schemes are relatively rare and most commonly occur in specialised accident and emergency departments (particularly ophthalmic), where many nurses have the relevant postregistration qualification and years of specialised clinical experience. Secondly, differences between the work of official and unofficial nurse practitioners in equivalent departments are relatively minor. Thirdly, the volume and range of nurse practitioner work in major general departments is small, reflected in the estimated small numbers of patients treated by nurse practitioners nationwide. Yet the presenting problems of patients attending major general or minor accident and emergency departments are broadly similar, despite the wide discrepancy in the proportion of patients managed by doctors and nurse practitioners in the two types of department. This may be explained partly by the greater severity of injury of patients in major departments, but other explanations are also possible. In major departments official nurse practitioners usually work to specific protocols governing the site and nature of injuries and the age of patients. Thus, many patients who would be treated by a nurse practitioner in a minor department will automatically be referred to a doctor in a major department with an official nurse practitioner scheme-children, for example. Restrictions on the ordering of radiographs and the automatic requirement that all patients should be seen by a doctor after $x$ ray investigation (we observed only one major department where this did not apply) also reduce the number of patients eligible for management by nurse practitioners.

Two other factors also prevent nurse practitioners fulfilling even the limited quota of practice allowed by their protocols: firstly, shortages of trained nurses other than nurse practitioners necessitate the diversion of designated nurse practitioners to other nursing tasks to keep the accident and emergency department running; and, secondly, when a doctor is present most patients are directed towards him or her, and the nurse practitioner is used only when there is an obvious shortage of doctors. The first factor tends to occur where there are official practitioners and the second where they function unofficially.

In its review of accident and emergency departments in England the National Audit Office called for guidance, based on existing good practice, for staff considering establishing nurse practitioner schemes.2. If the role of the nurse practitioner in accident and emergency departments is to become more clearly defined rather than to continue to develop sporadically and largely unofficially, as has been the case up till now, four issues must be considered.

Firstly, where official nurse practitioner schemes are in place staffing arrangements must ensure that the nurse practitioners can actually practise and are not diverted to other tasks.

Secondly, clear protocols should be drawn up and properly constituted audit arrangements made to monitor the outcome of an increased volume of treatment by nurse practitioners. Departments already commonly follow clear protocols in relation to potentially serious conditions like head injuries. Nurse practitioners are dealing with only a small number of such cases, but to what extent protocols are followed is not clear from this study. Any nurse, whether a designated practitioner or not, is personally accountable for his or her clinical decisions and practice..$^{2324}$ The need to follow clear guidelines in such cases is therefore obvious.

Thirdly, as well as establishing the degree of conformity to preset standards, auditing arrangements should compare the management of similar cases by nurse practitioners and junior doctors for both process and outcome. If the results are satisfactory the scope of work done by nurse practitioners and the criteria for selecting patients for management by them could expand at least to the level pertaining in some places already.

Finally, national training and accreditation for nurse practitioners should be discussed in the context of the moves to extend the role of nurses and to broaden the scope of their professional practice. ${ }^{23-25}$

We thank all accident and emergency consultants and nursing, managerial, and clerical staff who cooperated in these studies; Dr John Doar for advice on coding accident and emergency information; Lesley Thorpe, Jean Orme, and Lois Read for data preparation; Linda Westlake for analysing the survey data; Sheila Bray for typing, and colleagues in the uni and Dr Steve George for their comments on the manuscript. The work was funded by the Department of Health, which with Trent Regional Health Authority maintains the medical care research unit.

1 Morris F, Head S, Holkar V. The nurse practitioner: help in clarifying clinica and educational activities in A\&E departments. Health Trends 1989;21: $124-6$

2 Potter T. A real way forward in A\&E: developing the nurse practitioner role Professional Nurse 1990;5:586-8.

3 Burgess $\mathrm{K}$. A dynamic role that improves the service. Combining triage an nurse practitioner roles in accident and emergency. Professional Nurs 1992;7:301-3.

4 Waeckerle JF, Gaughan M, Billings R, McNabney WK. The emergency nurs as a primary health care provider-a retrospective study. Fournal of Emergency Nursing 1977;3:21-5.

5 Wildhalm SA, Anderson LA. Emergency nurse practitioners--motivators barriers and autonomy in role performance. Fournal of Emergency Nursing

6 Hayden ML, Davies LR, Clore ER. Facilitators and inhibitors of the emergency nurse practitioner role. Nursing Research 1982;31:294-9.

7 Powers MJ, Jalowiec A, Reichelt PA. Nurse practitioner and physician care compared for non-urgent emergency room patients. Nurse Practitioner 1984;9:39-52

8 Milner PC, Nicholl JP, Williams BT. Variation in demand for accident and emergency departments in England 1974-1985. F Epidemiol Communit Health 1988;42:274-8.

9 Davison AG, Hildrey ACC, Floyer MA. Use and misuse of an accident and emergency department in the east end of London. I R Soc Med 1983;76: $37-40$

10 Cliff KS, Wood TCA Accident and emergency services--the ambulan patient. Hospital and Health Services Review 1986;82:74-7.

11 Warren R. The other 99 per cent. Health Services fournal 1989;99:232-3.

12 McGaughey P, Melby V. Attendance at accident and emergency departments. Nursing Times 1991;87(41):51.

13 Shaw C, Hurst M, Stone S. Towards good practices in small hospitals-som suggested guidelines. Birmingham: National Association of Healt Authorities, 1988 .

14 Jones NP, Hayward JM, Khaw PT, Claoue CMP, Elkington AR. Function of an ophthalmic accident and emergency department: results of a six month survey. $B M \mathcal{F} 1986 ; 292: 188-90$

15 Royal College of Nursing Accident and Emergency Forum. Emergency nur practitioner--guidelines. London: Royal College of Nursing, 1990.

16 Yates DW. Nurse practitioners for accident and emergency? British fournal of Accident and Emergency Medicine 1987;2:10-1.

17 James MR, Pyrgos N. Nurse practitioners in the accident and emergency department. Arch Emerg Med 1989;6:241-6. 
18 Casualty Surgeons' Association. Accident and emergency department handbook. Loughborough: 3 M Healthcare Ltd, 1990.

19 Dean AG, Dean JA, Burton AH, Dicker RC. Epi Info Version 5: a word processing, database and statistics program for epidemiology on microcomputer. Stone Mountain, Georgia: USD Incorporated, 1990 .

20 Williams E, Pottle B. The ups and downs of accident and emergency. Nursing Times 1989;85(47):60-4

11 Burcher B, Elliot D A sampling errors manual. London: OPCS/HMSO, 1990.

22 National Audit Office. NHS accideit and emergency departments in England. London: HMSO, 1992.
23 United Kingdom Central Council for Nursing, Midwifery and Health Visiting. The scope of professional practice. London: United Kingdom Central Council, 1992

24 United Kingdom Central Council for Nursing, Midwifery and Health Visiting. Code of professional conduct. 3rd ed. London: United Kingdom Central Council, 1992.

25 Department of Health. The extended role of the nurse/scope of professional practice. London: Department of Health, 1992. (PL/CNO (92) 4.)

(Accpted 14 October 1992)

Regional transfusion centre preoperative autologous blood donation programme: the first two years

\author{
Martin R Howard, Catherine E Chapman, Judith A Dunstan, Christine Mitchell, Huw L Lloyd
}

\section{Abstract}

Objective-To assess the efficacy of a regional autologous blood donation programme.

Design-Clinical and laboratory data were collected and stored prospectively. Transfusion data were collected retrospectively from hospital blood bank records.

Setting-Northern Region Blood Transfusion Service and 14 hospitals within the Northern Regional Health Authority.

Subjects-505 patients referred for autologous blood donation before elective surgery.

Main outcome measures-Patient eligibility, adverse events from donation, autologous blood units provided, and autologous and allogeneic blood units transfused within 10 days of operation.

Results-Of 505 patients referred, 354 donated at least one unit. 78 of 151 referred patients who did not donate were excluded at the autologous clinic, mostly because of anaemia or ischaemic heart disease. In 73 cases the patient, general practitioner, or hospital consultant decided against donation. 363 autologous procedures were undertaken. In 213 $(59 \%)$ cases all requested units were provided. The most common reasons for incomplete provision were late referral or anaemia. Adverse events accompanied 24 of 928 donations $(2 \cdot 6 \%)$. Transfusion data were obtained for 357 of the 363 procedures. 281 donors were transfused; autologous blood only was given to 225 , autologous and allogeneic blood was given to 52 , and allogeneic blood only was given to four. 648 of $902(72 \%)$ units of autologous blood were transfused. Complete provision of requested autologous units was followed by allogeneic transfusion in 12 of 208 procedures $(5 \cdot 8 \%)$. Incomplete provision was followed by allogeneic transfusion in 44 of 149 procedures $(30 \%)$.

Conclusions-This study shows the feasibility of a regional autologous transfusion programme. Autologous donors only infrequently received allogeneic transfusion. Patients should be appropriately selected and referred early.

\section{Introduction}

Autologous blood provides an alternative to blood from volunteer donors for patients undergoing elective surgical procedures. Although autologous transfusion has been practised intermittently for 100 years, there has recently been increased interest in the procedure. This has arisen partly from a heightened public awareness of the infective risk of blood transfusion and partly from the increasing demand for blood from volunteer donors. Potential advantages of autologous transfusion include the avoidance of blood transmitted infection, alloimmunisation, and transfusion related lung injury.
There is a small but definite risk of acquiring $\vec{\omega}$ infection from transfused allogeneic blood. Dodd 0 suggested that about three in 10000 blood recipients in 3 . the United States contract serious or fatal transfusion $\omega$ transmitted infection.' Estimates of the risk of HIV transmission by transfusion in the United States range from one in 225000 per unit transfused ${ }^{2}$ to one. $v$ in $60000 .^{3+}$ We have estimated the risk of HIV-1 $\vec{A}$ transmission by allogeneic blood in the United 8 Kingdom using Hickman's modification of a formula응 proposed by Ward et al. ${ }^{56}$ Using known incidences of HIV-1 antibody positivity between 1985 and 1991 of $N$ $0.004 \%$ in first time donors and $0.001 \%$ in repeat donors, ${ }^{7}$ we estimate the risk of HIV-1 transmission $\varnothing$ in the United Kingdom as one in 300000 per unit transfused.

Hepatitis B remains a transfusion risk despite donor screening, but the annual number of acute cases in England and Wales is fairly small. On average 10 cases of acute hepatitis B in which patients had a recordedo history of transfusion (with or without surgery) in the United Kingdom in the six months preceding diag-o nosis were reported to the Public Health Laboratory Service Communicable Disease Surveillance Centre each year between 1985 and 1990. This excludes $\overrightarrow{\overrightarrow{0}}$ patients known to have surgically acquired infection $\exists$ (J Heptonstall, personal communication). Donahue et al reported a risk of acquiring post-transfusion? hepatitis C of one per 3000 units transfused in the United States. ${ }^{8}$ The assay used for screening donations for hepatitis $\mathrm{C}$ antibody in their study has already been 0 routinely replaced in Britain and the United States by a more sensitive assay, which is likely to further reduce 8 this risk.

Approximately $0 \cdot 3 \%$ of routine blood donors haveo unexpected red cell alloantibodies. ${ }^{\circ}$ Such antibodies usually arise after allogeneic transfusion or pregnancy and may complicate future transfusion. Transfusion $\rightarrow$ related lung injury is a life threatening complication of allogeneic transfusion which may be avoided by autologous transfusion. ${ }^{10}$

We report the first two years' experience of $a^{\sigma}$ preoperative autologous blood donation programme inco a regional transfusion centre in the United Kindgom. We examine factors which prevented or limited pro- $\stackrel{\oplus}{?}$ vision of autologous blood and assess the incidence of 0 subsequent autologous and allogeneic transfusions in autologous donors.

\section{Patients and methods}

The autologous blood donation programme waso open to patients in the Northern Regional Health Authority who were waiting for a surgical procedure for which blood would usually be cross matched. Programme documentation was distributed to hospitals within the region. Hospitals within 40 miles $(65 \mathrm{~km})$ 